Editorial Note

\title{
Attempting to Bring Valuation and Politics Together - The Politics of Valuation Studies at a Series of Sessions in Copenhagen
}

Claes-Fredrik Helgesson, Monika Krause, and Fabian Muniesa

Is 'valuation' anything at all? Apart from a strange excuse for doing things in certain ways? 'Valuation Studies' means 'Nothing-at-All Studies'!

- Participant, “The Politics of Valuation”, 33 ${ }^{\text {rd }}$ EGOS Colloquium 2017

Claes-Fredrik Helgesson, Department of Thematic Studies-Technology and Social Change, Linköping University, claes-fredrik.helgesson@liu.se

Monika Krause, Department of Sociology, London School of Economics, m.krause@lse.ac.uk

Fabian Muniesa, Centre de Sociologie de l'Innovation, Mines ParisTech, fabian.muniesa@mines-paristech.fr

(C) 2017 Authors

LiU Electronic Press, DOI 10.3384/VS. 2001-5992.17511

http://valuationstudies.liu.se 
The question was duly raised, in a variety of manners, in a recent discussion in Copenhagen on 'the politics of valuation' that turned intermittently into a conversation on 'the politics of valuation studies'. ${ }^{1}$ Is it not becoming fashionable, in several academic circles, to frame everything and nothing as 'valuation'? What does this say about the health, or rather the lack thereof, of the endeavours organised around 'valuation studies' as an alleged field, trend or approach? The social sciences appear to be saturated with valuation as a problem, topic, practice, label, and whatnot. Yet, this apparent saturation seems to be aptly justified by the mounting reality of a valuation syndrome in contemporary liberal societies, with all kinds of problems being incessantly presented-and 'solved'-in terms of valuations. Since valuation seems to stand today as the ultimate key to social policies, economic institutions, environmental measures and democratic processes, it probably warrants some form of social-scientific compulsion to perform critical analyses. But the question of the specificity of the subject matter remains open.

There has in recent years been a surge of workshops, conference sessions and tracks, special issues, books and calls for papers in which the study of valuation as a social practice operates as duct-tape, leitmotiv, or key driver (for examples of this surge, see Jürgenmeyer and Krenn 2016; Otto and Dalsgaard 2016). This is not the moment and place to submit this intriguing academic reality to anthropological or sociological scrutiny (see Muniesa and Helgesson 2013; Doganova et al. 2014; Boltanski and Esquerre 2015). Yet, the sessions in Copenhagen produced interesting ideas on how an attempt at specifying an angle on valuation in the terms of 'the politics of' valuation also would attend to the reflexive sides of such a process of examination.

1 The remarks presented in this note are grounded on the presentations and discussions offered by participants to Sub-Theme 28 "The Politics of Valuation" (convened by Claes-Fredrik Helgesson, Monika Krause and Fabian Muniesa), 33rd EGOS Colloquium (European Group for Organization Studies), Copenhagen (Denmark), 4-6 July 2017. We thanks all contributors for their work: Afshin Mehrpouya, Alexandre Mallard, Amalie M. Hauge, Ana Carolina R. Macatangay, Andrea Mennicken, Angèle Christin, Brice Laurent, Brieuc Petit, Daniel Neyland, David Yarrow, Delphine Gibassier, Désirée Waibel, Diane-Laure Arjaliès, Ebba Sjögren, Fabian Muniesa, Frank Meier, Hans Kjellberg, Henrik Bach Mortensen, Hyojung Sun, Ida Schrøder, José Ossandón, Julia Kirch Kirkegaard, Katherine Robinson, Kathia Serrano Velarde, Klaus Lindgaard Høyer, Koray Çalışkan, Liliana Doganova, Linus Johansson Krafve, Liz McFall, Mariam L. Krikorian, Mette Mogensen, Monika Krause, Nicole Gross, Peer C. Fiss, Peter Karnøe, Philip Roscoe, Rita Samiolo, Robert Cluley, Sarah Wadmann, Stefan Schwarzkopf, Stoyan V. Sgourev, Subhadeep Datta, Susi Geiger, Sveta Milyaeva, Thomas Reverdy, Thorsten Peetz, Véra Ehrenstein, Vern L. Glaser. The conference programme is available from the archives of the EGOS website, https:// www.egosnet.org/. The hashtag \#PoliticsVal was used for live tweeting during the sessions. 
The fact that valuation 'entails politics writ large and small' was presented as an opening premise for our conference sessions. This is in one sense a trivial claim: the establishing, negotiating, delineating and ordering of values are intrinsically political. Yet, the untangling of the political articulations of such processes is not trivial. The call for participants therefore stressed the aim to gather empirical and conceptual explorations of the multifaceted politics of valuation, including both the politics in valuation practices and the role of valuation practices in the distribution of different kinds of resources. ${ }^{2}$ We explicitly aimed to include contributions using a variety of conceptual and methodological approaches and exploring a variety of empirical settings. Among the questions devised as evocative siren calls were: What different forms of politics are part of and performed by practices of valuation? What can different approaches within social theory and pragmatist studies of valuation practices bring to our appreciation of these multifaceted politics? Are there conceptual gains in the interface between different approaches to the study of valuations?

The assembled contributions visited a broad range of sites, working within several methodological and conceptual approaches. Both economic and non-economic valuations were in focus, as where mundane under-most-radars politics and front-page POLITICS. Although various qualitative methods dominated, there was no sense of methodological unity. The 'politics of' served as a communicational token rather than as a full fledged concept. Nevertheless, it allowed identifying a number of specificities of valuation understood as a political operation.

Technology was the most dominant among the specificities examined. The systems, devices, instruments and infrastructures that underpin various kinds of valuation (rating, pricing, ranking, accounting, funding, and assessing) were deemed 'political' in at least two, partly contrasting senses. One would revolve around the idea of considering technology as the medium for the political control of things: a pricing scheme, a ranking display, a valuation formula or an assessment method are considered as political technologies insofar as their rationale determines the distribution of resources and opportunities. Another kind of specificity identified through 'politics of valuation' was situations of disruption, conflict, dissent and controversy, rather than of control. Here, it made technologies and entailed stakes visible and open to critical consideration. The extent to which these different directions correspond to different political philosophies is patent, although not always examined. There are

2 https://www.egosnet.org/jart/prj3/egos/main.jart?rel=de\&reservemode=active\&content-id=1493586858301\&subtheme_id=1442568082016 accessed September 29, 2017. 
certainly works in which the political is just equated to power, and others in which it is associated with argument and dissent. A central task when developing an agenda for the study of the politics of valuation would be to explore the possibility to fruitfully draw on domains such as democratic theory or political theology for the examination of valuations as political.

But, as we suggested above, the discussion can additionally be about or include the politics of valuation studies itself. There is a widely acknowledged reflexive sense of the political dimension of the method and scope of social-scientific inquiry. Coming back to our claim about how intriguing and disconcerting the culture of 'solving' all kinds of 'problems' in terms of valuation is, one is entitled to ask what alternatives for 'solution' are left out when things get framed in terms of valuation. A potentially pertinent issue here would be to ask how, if at all, valuation studies can problematize this very frame and, to up the stakes further, if it can enable the bringing in of other alternatives.

One possible avenue for working on a politics of valuation studies emerging from the Copenhagen sessions centres on comparison. There was a call both to engage in more comparisons, and to think harder about how they are done in studies of valuations. Can the specificity of a properly political approach to valuation studies reside just there? We do not know. But we do know that comparisons are both an object and a method for valuation studies, as many examples in current research illustrate. How do the sensibilities we can use when studying comparisons translate when we ourselves do comparisons? In the spirit of recent work on comparison (Deville, Guggenheim and Hrdličková 2016a; see also Fox and Gingrick 2002; Scheffer and Niewoehner 2012), one can ask researchers in valuation studies to compare the way they themselves engage in comparison. As pointed out in the tradition of the sociology of science, the business of establishing a 'comparator' with which we could make this more visible is complex (Deville, Guggenheim and Hrdličková 2016b).

As a method, comparison is sometimes mobilised as a tool for denaturalization: that is, as a way to demonstrate how similar things are different in different sites, or how something deemed regular is not when contrasted against something else. Juxtaposing cases is certainly a way to make differences more salient and therefore more politically salient, at least in the reader's mind. The unit of comparison and its characterization-what is the saliency about-constitutes a central element in the politics of valuation studies. We note in this respect that research tends to be framed most explicitly as comparative when they take nation-states as a unit of analysis. Partly because of conventions, which treat the unit of comparison as a cause (Krause 2016), crossnational comparisons remind us of the role of the state as a crucial vector around which the politics of valuation crystallize. 
The discussion in Copenhagen covered some ways in which the topic of the politics of valuation, primarily considered throughout the discussion as an angle on the political rationale and determination of valuation technologies, meets a more 'traditional' (jurisdictional, territorial) sense of politics. If valuation studies understood as a field has indeed been a "strange excuse for doing things in certain ways", it has at least been an excuse for doing things in specific ways, leading scholars to shed light on the role of practices and technologies previously overlooked. Perhaps, though, we can ask about valuation studies, like about any other project, whether in some ways it has been 'a gain in particular and a separation in general'? A perhaps unavoidable (perhaps not) 'increase in power leading only to a progressive increase in impotence'? The sessions in Copenhagen happened to close with a slide with these words from Robert Musil's The Man Without Qualities, leaving the agenda open for further attempts to bring valuation and politics together in different senses and in different empirical settings.

\section{References}

Boltanski, Luc and Arnaud Esquerre. 2015. "Grappling with the Economy of Enrichment." Valuation Studies 3 (1): 75-83

Deville, Joe, Michael Guggenheim and Zuzana Hrdličková, eds. 2016a. Practising Comparison: Logics, Relations, Collaborations. Manchester: Mattering Press.

Deville, Joe, Michael Guggenheim and Zuzana Hrdličková. 2016b. "Same, Same but Different: Provoking Relations, Assembling the Comparator." In Practising Comparison: Logics, Relations, Collaborations, edited by Joe Deville, Michael Guggenheim and Zuzana Hrdličková, 99-129. Manchester: Mattering Press.

Doganova, Liliana, Martin Giraudeau, Claes-Fredrik Helgesson, Hans Kjellberg, Francis Lee, Alexandre Mallard, Andrea Mennicken, Fabian Muniesa, Ebba Sjögren and Teun Zuiderent-Jerak. 2014. "Valuation Studies and the Critique of Valuation." Valuation Studies 2 (2): 87-96.

Fox, Richard G., and Andre Gingrich. 2002. Anthropology, by Comparison. London: Routledge.

Jürgenmeyer, Julian, and Karoline Krenn. 2016. "Classification Situations: A New Field of Research for Valuation Studies.” Valuation Studies 4 (2): 177-189.

Krause, Monika. 2016. "Comparative Research: Beyond Linear-Causal Explanation." In Practising Comparison: Logics, Relations, Collaborations, edited by Joe Deville, Michael Guggenheim and Zuzana Hrdličková, 45-67. London: Mattering Press. 
Muniesa, Fabian, and Claes-Fredrik Helgesson. 2013. "Valuation Studies and the Spectacle of Valuation." Valuation Studies 1 (2): 119-123.

Otto, Ton, and Steffen Dalsgaard. 2016. "Guest Editorial: Alternative Valuations." Valuation Studies 4 (1): 1-9.

Scheffer, Thomas, and Jörg Niewöhner, eds. 2010. Thick Comparison: Reviving the Ethnographic Aspiration. Leiden: Brill.

Claes-Fredrik Helgesson is co-Editor-in-Chief of Valuation Studies and Professor in Technology and Social Change at Linköping University, Sweden. He is co-editor with Isabelle Dussauge and Francis Lee of the volume Value Practices in the Life Sciences and Medicine (Oxford University Press, 2015). Helgesson is currently concluding with Francis Lee the research project 'Trials of Value' which explores valuation practices in the context of experimental design in biomedical research.

Monika Krause teaches at the London School of Economics. She is the author of The Good Project: Humanitarian NGOs and the Fragmentation of Reason (Chicago University Press, 2014). She is an editor of Fielding Transnationalism (Wiley, 2016) (with Julian Go) and of Social Theory Now (Chicago University Press, 2017) with Claudio Benzecry and Isaac Reed.

Fabian Muniesa, a researcher at the Centre de Sociologie de l'Innovation (Mines ParisTech), is part of the editorial board of Valuation Studies (co-Editor-in-Chief) and the co-author of Capitalization: A Cultural Guide (Presses des Mines, 2017). 